\title{
De la ambigüedad del mito
}

Sergio Espinosa Proa

Universidad de Zacatecas - México sproa52@hotmail.com

Recibido: 4-mayo - 2018 / Aprobado: 31 - mayo - 2018

\section{Resumen}

El presente ensayo aborda la categoría "mito" desde un enfoque filosófico. El autor plantea comprender el mito desde la función interpretativa con que se construye el mundo, la civilización, el lenguaje, la política, la verdad y la razón misma. El autor postula retomar el análisis del mito más allá de las lecturas lineales de la psicología histórica y de la teología. El mito posee una arquitectura específica que preside la organización del mundo, de lo humano y lo divino, en todas las culturas; sin ésta, la filosofía misma no hubiese existido. La modernidad requiere precisamente de un análisis del mito desde su propio ordenamiento semántico y pragmático. El misterio y el peligro de lo irracional no tiene que ser ignorado ni combatido, es necesario comprenderlo.

Palabras clave: mito, tragedia, filosofía, psicohistoria.

\section{Abstract}

This essay addresses the category "myth" from a philosophical approach. The author raises understand the myth from the interpretive function with which the world is built, civilization, language, politics, truth and reason itself. The author postulates resume the analysis of myth beyond the linear readings of historical psychology and theology. The myth has a specific architecture that presides over the organization of the world, 
the human and the divine, in all cultures; without it, philosophy itself had not existed. Modernity requires precisely an analysis of myth from its own semantic and pragmatic system. The mystery and danger of the irrational not be ignored or fought, you need to understand.

Keywords: mito, tragedia, filosofía, psicohistoria. 
a filosofía constituye, en su origen, un supremo esfuerzo de supresión de la ambigüedad lógica según la cual se presenta lo humano como enigma sin solución. La tragedia, por deliberación o desinterés, deja inacabada la efigie de este ente situado a la vez dentro y fuera del mundo: una interrogación abierta, una herida en y del ser. ¿Qué vínculo subsiste con el pensamiento mítico, por un lado, y con la filosofía, por el otro? El mito, por su persistencia en el tiempo, ha podido ser concebido como la matriz de toda invención o creación cultural; es el huevo primordial de Oparin, de cuya ruptura brotará la magia, primero, y, poco después, la filosofía y la ciencia, en una rama paralela a la religión y el arte: unidad de lo consciente y lo inconsciente, de lo racional y lo irracional, de lo afectivo y lo intelectual, que con la aparición y evolución de la civilización y de la historia se escinde sin dar lugar, hasta el momento, a una nueva conjunción en equilibrio. Se trata de una bifurcación lógica: pues existe, de una parte, lo mostrable, y, de otra, lo demostrable. ${ }^{1}$ ¡Una idea bastante mítica del mito! Éste se presenta como una especie de ruido de fondo, el átomo primigenio de la creación cultural; sus categorías -invención de seres sobrenaturales, repetición ritual, permeabilidad social, suspensión del espacio-tiempo profano y de sus divisiones, indistinción de lo humano y lo no humano, de lo vivo y lo muerto... decaen y resucitan, transformadas, en los diferentes ámbitos de la creación cultural: el mito es la fuente y la desembocadura de todo lo humano. Es ésta una definición quizás excesiva; en rigor, se trata más bien de una teología del mito. Parece claro que debemos comenzar en otra parte (aunque volvamos aquí). Platón es, por cierto, el primer filósofo en pensarlo; y su examen -en su profundidad y en su ambivalencia- constituye el obligado punto de partida. El mito, para el filósofo, adolece de dos defectos fatales: en primer lugar es inverificable y en segundo su argumentación procede de manera desordenada, azarosa, contingente; la filosofía, por el contrario, se rige tanto por la verificabilidad como por la consistencia argumentativa. Pero es justo reconocer, cosa que sin reparos hace Platón, que el mito es superior a la filosofía en un rasgo esencial: si es cuestión de persuadir, e incluso de hechizar, nada como su eficacia: el mito es música para los oídos. "Aunque sea un discurso inverificable que no pretende un carácter argumentativo, el mito está investido de una eficacia mayor aun cuando transmite un saber de base compartido por todos los miembros de una colectividad dada donde, de hecho, puede desempeñar el papel de instrumento de persuasión con un alcance universal. Única alternativa a

1 Cfr. Eduardo Giqueaux, El mito y la cultura, Ediciones Castañeda, Buenos Aires, 1979, p. 14. 
la violencia, permite la preeminencia en el alma humana de la razón sobre la parte mortal, y garantiza en la ciudad la sumisión de la mayoría a las prescripciones del fundador de la ciudad o del legislador, que son filósofos". ${ }^{2}$ En resumen, que el mito sea falso importa menos que el hecho de que sea (política y éticamente) inútil. No sabemos si es verdad lo que cuenta el mito, pero si ayuda a regular la conducta de los individuos, si los torna obedientes a la ley, no hay razón para condenarlos. La filosofía es necesaria para el que manda, pero los que obedecen pueden pasársela muy bien alimentándose de mitos. ¡ Realismo político!

\section{II}

A diferencia de la tragedia y la filosofía, el mito no es un género literario; es un relato no escrito, un discurso apoyado en la memoria que cuenta historias dignas de ser contadas, es decir, conservadas y transmitidas de generación en generación. Como afirma Platón, es inverificable porque trata de entidades imaginarias o, dicho más enfáticamente, inexistentes: dioses, démones, héroes, personajes legendarios, monstruos, habitantes del Hades... Sus referentes son impermeables a la inteligencia y a la sensibilidad. Así aparecen, al menos, en una definición "operatoria" (que es la empleada por Luc Brisson): más allá no se puede ir. La insuficiencia de este ángulo es palmaria; no nos dice qué es sino qué no es un mito: un cuento no escrito que borda sobre seres que no existen. ¿Posee una lógica, una racionalidad propia? No lo sabemos; tendremos que acudir a otro lugar. Una vez más, la psicología histórica de Jean-Pierre Vernant, Pierre Vidal-Naquet y Marcel Detienne se presta como plataforma ideal: su premisa básica -quizá dotada de un remanente ligeramente idealista- es que ninguna creación humana es efecto del azar: hasta en lo más simple o absurdo subyace un régimen pensante. Simple o absurdo a nuestros ojos, que bizquean y se desenfocan como cualesquiera otros. ¿Qué voluntad subtiende la lógica del mito? Sin duda, una voluntad de comprensión, de ordenamiento del caos sensorial, un paso de danza en la oscuridad. A semejanza de la tragedia, el mito traza figuras ambiguas y equívocas en la superficie y el espesor de lo desconocido. La razón no acampa tan lejos; sólo procura erradicar esa ambigüedad y esa equivocidad por considerarlas nocivas para asegurar el éxito en su empeño de inteligibilidad. No es que la imaginación se halle ausente en la razón: lo que hace es cambiar de forma y, con ello, de estatuto. Si la lógica del mito es cualitativa, diferenciada, jerarquizada y proliferante, diríase orgánica -su modelo es la naturaleza-, la lógica de la razón -fuente de la filosofía y la ciencia- es geométrica, homogénea, reversible y abstracta. Tal vez desoriente un poco la idea de que hay muchas formas de la razón; la filosofía nos ha habituado a concebirla unívocamente; mas lo importante es conceder que, a semejanza del sueño, el trance y la locura, el mito está estructurado como un lenguaje.

2 Luc Brisson, Platón, las palabras y los mitos, ¿cómo y por qué Platón dio nombre al mito?, trad. José Ma. Zamora Calvo, Abada Editores, Madrid, 2005, p. 164. 
Enseguida, admitir que tampoco existe El mito; descifrar su estructura significa -al igual que con la Tragedia- limitarse a un ámbito geohistórico: Grecia en el siglo VI a. C. No es lícito, adoptada esta perspectiva, proponer una estructura universal. Por lo demás, esa estructura o ese diseño emerge al aplicar el método -la psicología histórica- en un mito anómalo: en una versión escrita, estabilizada, "oficial". Hechas estas salvedades, ¿qué articulación descubre el análisis del mito hesiódico de las razas?

III

El mito posee una arquitectura específica. En absoluto se trata de referir una historia lineal; el relato está estructurado en estratos y oposiciones que desconocen o sobrevuelan la sucesión meramente cronológica. "Esta arquitectura que regula el ciclo de las edades es también la que preside la organización de la sociedad humana y del mundo divino; el 'pasado', tal como le compone la estratificación de las razas, se estructura sobre el modelo de una jerarquía intemporal de funciones y de valores". ${ }^{3}$ Georges Dumézil ha mostrado, para todo el horizonte indoeuropeo, una tripartición (inconsciente) regida por la Soberanía -legítima-, la Fuerza -militar- y la Fertilidad: son los tres estratos (reyes, guerreros, labriegos) que se leen en la elaboración que Hesíodo practica sobre este mito. Así como Freud descubre el "trabajo del sueño", el análisis psicohistórico encuentra un "trabajo del mito" consistente en establecer un sistema de correspondencias flexible y a la vez riguroso que, al filo de la narración, simboliza lo real: en el fondo, el mito griego, al menos tal y como lo articula Hesíodo, es un intento perfectamente racional de pensar la contradicción fundamental que atraviesa al mundo arcaico, a saber, la oposición entre Diké (lo justo) e Hybris (la desmesura). No se nos escapará que lo que hace Hesíodo es ya un re-pensar el material mítico: se sitúa en el surco que conducirá primero a la tragedia (y a la sofística) y enseguida a la filosofía. Desde luego, esta lectura acaso desaforadamente estructuralista ha sido impugnada desde el principio; como no podemos entrar en el detalle de la crítica, baste decir que se le achaca un fatal descuido del componente diacrónico en aras de la sincronía (tara congénita del enfoque estructuralista). Lo interesante es que Vernant establece una correspondencia muy firme entre el pensamiento mítico y la sociedad aristocrática griega, cuya crisis desembocará en la invención de la democracia. A esta sociedad totalmente nueva ya no le servirá la representación mítica y tendrá que darle lugar a la tragedia, primero, y a la filosofía, poco después. El examen del mito de las razas en Hesíodo no es un ejercicio puramente académico: defiende una tesis política, la justificación de la superioridad de la democracia sobre la tiranía -y, por extensión, de la filosofía sobre la tragedia y de ésta sobre la mitología-. Desde el principio, los dados están cargados. Pero, más allá de esta toma de posición, tan válida como cualquier otra, ¿se sostiene la idea de

3 Jean-Pierre Vernant, Mito y pensamiento en la Grecia antigua, trad. J. D. López Bonillo, Editorial Ariel, Barcelona, 2001, p. 44 . 
que el mito piensa aristocráticamente y la filosofía lo hace democráticamente? Sería preciso, a fin de responder, detenernos en los mecanismos específicos merced a los cuales, dentro del mito y de su lógica, son concebidos el espacio y el tiempo -y, en particular, la memoria-, el trabajo y la técnica, la imagen (o el doble) y, por último, la personalidad (o la subjetividad).

\section{IV}

Insistamos: la perspectiva de estos autores es psico-histórica. Es decir: pos-mítica y pos-trágica: sin la filosofía jamás habría tenido lugar. Es una postura que tiende a remarcar las correspondencias de la estructura social con la mentalidad que la acompaña. El surgimiento de la filosofía (e incluso de la tragedia) resulta impensable en una sociedad monárquica como la de Micenas (o Persia, o Egipto). Fue necesaria una catástrofe del sistema jerárquico antiguo para hacer posible la institución de la polis, un giro que involucra -presupone y alimenta- la secularización del pensamiento. Todo se transforma en este trance: las instituciones y sus representaciones, las prácticas y sus legitimaciones. El lugar vacío dejado por el Rey será ocupado por la argumentación, un debate público ejercido abierta y libremente en el Ágora. El mito, en suma, ha dejado de ser funcional; de hecho, se ha vuelto casi ininteligible. La polis reclama su propia autorreflexión, que ya no le proporciona la imaginación mítica, articulada sobre la figura del soberano, del Dueño y Señor de la vida y la muerte. La arkhé (el poder) se humaniza, se recarga en la discusión y el acuerdo: los conflictos no son dirimidos por un individuo que concentra el poder divino, sino por un conjunto, por una multiplicidad continuamente renovada. Al inventar la polis, Grecia genera una atmósfera propicia a la palabra, abriéndose a una transmutación de la rivalidad física en competencia intelectual. Nace la política, pues, y con ella la retórica (o la sofística), como arte de la persuasión, y la filosofía, como una interrogación perpetua sobre la que la misma política ejercerá de mil maneras su sibilina violencia. El rey ha muerto, pero la diké, aterrizada en leyes y discursos, en normas y reglas sometidas a humano escrutinio, entrará al relevo. La religión no desaparece pero, convertida en culto mistérico, se repliega en la interioridad individual. En ese doblez aparece la filosofía: entre la sabiduría mistérica y la algarabía del Ágora, entre la penumbra del secreto y la luminosidad de lo público. De un lado, las sectas órfico-pitagóricas; del otro, la sofística profana. Una ambigüedad de la que nunca ha podido (o deseado) librarse. Como quiera que sea, el nuevo orden cívico -porque es un orden, o procura serlo- implica una adopción, una adaptación, una naturalización, una socialización de la diké: entre la monarquía y la anarquía, la iso-arquía. "Con Solón, Diké y Sophrosyné, bajadas del cielo a la tierra, se instalan en el Ágora". " No sin problemas, no sin provocar efectos indeseados; la formación de sectas ascéticas cuasifanáticas es uno de ellos. Pero el movimiento de raciona-

Jean-Pierre Vernant, Los orígenes del pensamiento griego, trad. M. Ayerra, EUDEBA, Buenos Aires, 1984, p. 69. 
lización -sustitución de la fuerza por la persuasión, de la violencia por la ley, de la cólera y la ambición por la prudencia y la mesura- continuará su marcha: la Grecia se aburguesa.

\section{V}

"Nada existe que no sea naturaleza, physis". ${ }^{5}$ El universo se aplana, se hace asequible, se vulgariza. "No es lo original lo que ilumina y transfigura lo cotidiano; es lo cotidiano lo que hace inteligible lo original, ofreciendo modelos para comprender cómo se formó y ordenó el mundo". ${ }^{6}$ Sí, pero la lógica del mito prosigue su andadura en terreno profano. ¿Hasta la fecha? La physis misma exhibe su herencia, su entraña mítica. Los presocráticos, sin trazar teogonías a la usanza hesiódica, piensan con categorías impuras; mitad razón, mitad fábula. El clima, ciertamente, ha cambiado: los misterios se han convertido en problemas, los enigmas se han hecho accesibles a la inteligencia humana. La genealogía retrocede ante la geometría, la teología ante la logología. Sí, pero parcialmente, y circunscrito a pequeños segmentos de la sociedad: a sus cohortes ilustradas. Que ya no se invoque la sucesión de los dioses, que se hable ya sólo de leyes naturales y fuerzas impersonales, ¿modifica de raíz la concepción general del mundo? Vernant piensa que sí: el mito es solidario de la soberanía, de la realeza, del régimen despótico; todo gira en torno de semejante ordenamiento vertical y jerárquico. Extinguido éste, ¿qué futuro le resta? Ninguno, salvo la inesperada e indeseable resurrección del despotismo. El mito de la psicohistoria -su lógicaposee los rasgos siguientes: ${ }^{7} 1$. El mundo está jerárquicamente ordenado. El poder se confunde con la voluntad de sumisión, es decir, de dominación. 2. En cuanto tal, no es producto del azar, de un juego inocente de fuerzas, sino que ha sido instituido, instalado, "instaurado dramáticamente por la intervención de un agente". 3. Ese agente, necesariamente sobrenatural, ejerce un dominio absoluto sobre todo cuanto existe: es su soberano, su Señor. ¡Maravillosa descripción del cosmos cristiano! El diagnóstico final -la autopsia- sobre la mitología griega parece haberse realizado en otro cadáver; en un cadáver que goza de una salud envidiable. Con este resultado, todo el análisis queda seriamente comprometido. La lógica del mito se fundió en cierto momento, inadvertidamente, con la teo-lógica, una infección contraída siglos más tarde en el desierto sirio-palestino. No se entiende, por decir lo menos, por qué, en un régimen eminentemente despótico, no existió una Iglesia formal en las poleis griegas, una casta sacerdotal, un libro sagrado, una tentación inquisitorial, un fanatismo social, tal como se produjo efectivamente en la cultura judeocristiana. No se entiende, quizás, porque la psicohistoria de Vernant asimila de forma muy precipitada, y por tanto indebida, la mito-lógica con la religión.

5 Ibid., p. 82.

6 Ibid., p. 83.

7 Ibid., p. 92 


\section{VI}

Platón redujo el mito a su mínima expresión (inverificabilidad e incoherencia); la escuela de psicología histórica -racionalista y democrática, según se ha visto- terminó confundiéndolo con la teología. Por fortuna, no son las únicas vías de acceso a su núcleo; de hecho, en la actualidad existen demasiadas, lo cual ha llegado a erigirse como un verdadero problema. Es probable que el mito sólo al mito entregue su secreto (sospecha que ha movilizado buena parte de la obra de Claude Lévi-Strauss y, más recientemente, la de Hans Blumenberg). La verdad sea dicha: no todo en él revela un sistema de legitimación del despotismo (asiático o europeo), ni siquiera en la teogonía de Hesíodo. La imaginación mítica se extiende a un más allá de la historia, a un más allá de la religión; se confunde, eso sí, con la mentalidad arcaica o primitiva, con el "pensamiento salvaje": con todo aquello que, al decir de Nilsson, se encuentra afuera o por debajo de la actividad técnica. Toda Ilustración se verifica en la superficie y en sectores más bien reducidos de la población; su alcance, a pesar de ciertos progresos espectaculares, es muy precario. El famoso paso del mito al logos aparece, en Grecia, como el reemplazo (parcial) del régimen genealógico por una proyección geometrizante de las cosas. No hay ni más ni menos realidad en una $\mathrm{u}$ otra, a pesar de lo que ha dicho William James: que es en "los estratos más oscuros y ciegos del carácter donde podemos sorprender auténtica realidad en formación" 8 Es una indicación notable: lo real no se "forma" en la luminosidad de la conciencia, sino ahí donde ella parpadea o está ausente. Dejemos por un momento esta discusión; contentémonos por lo pronto observando que los personajes y peripecias del mito no son menos verdaderos -aun perteneciendo a otro orden semántico y pragmático- que los axiomas y ecuaciones de la geometría: es una diferencia de profundidad, no de veracidad. La Ilustración ática presenta numerosas semejanzas con la europea (y americana) del siglo XVIII; cada una se va imponiendo con dificultad y cada una genera sus contracorrientes, reflujos que en ambos casos tienen que ver con la respectiva atmósfera mítico-religiosa de la que se desprenden. Los análisis de la Escuela de Francfort siguen brindando jugosos frutos; la "sociedad abierta" prohija a sus enemigos. La postura de estudiosos como E. R. Dodds es acaso más sobria y circunspecta; la Ilustración moderna tiene mucho que aprender de la antigua por un aspecto esencial: los racionalistas griegos "fueron profundamente conscientes del poder, el misterio y el peligro de lo Irracional. Pero sólo podían describir lo que acontecía por debajo del umbral de la conciencia en lenguaje mitológico o simbólico". A los modernos -si no quieren incurrir en una regresión semejante a la de la época helenística- les toca cobrar conciencia de su fuerza. Ante lo irracional, ni combatirlo ni ignorarlo: comprender su necesidad y quizás, a fin de cuentas, establecer con él nuevas y más fecundas alianzas. 


\section{Referencias}

Brisson, Luc (2005). Platón, las palabras y los mitos, ¿cómo y por qué Platón dio nombre al mito? Trad. José Ma. Zamora Calvo. Madrid: Abada Editores.

Dodds, E. R. (1981). Los griegos y lo irracional. Trad. M. Araujo. Madrid: Alianza Editorial.

Giqueaux, Eduardo (1979). El mito y la cultura. Buenos Aires: Ediciones Castañeda. Vernant, Jean-Pierre (1984). Los orígenes del pensamiento griego. Trad. M. Ayerra. Buenos Aires: EUDEBA. . (2001). Mito y pensamiento en la Grecia antigua. Trad. J. D. López Bonillo. Barcelona: Editorial Ariel. 